\title{
Psychiatric morbidity in pain conditions: Results from the Singapore Mental Health Study
}

\author{
Mythily Subramaniam MBBS MHSM, Janhavi Ajit Vaingankar MSc, \\ Edimansyah Abdin PhD, Siow Ann Chong MBBS MMed MD FAMS
}

\author{
M Subramaniam, JA Vaingankar, E Abdin, SA Chong. Psychiatric \\ morbidity in pain conditions: Results from the Singapore Mental \\ Health Study. Pain Res Manag 2013;18(4):185-190.
}

BACKGROUND: Chronic pain is a common problem among the general population and has been found to be associated with psychiatric disorders in studies based on both clinical samples and epidemiological surveys. OBJECTIVES: To establish the prevalence, correlates and comorbidities of chronic pain disorders among the adult population of Singapore.

METHODS: The data used in the present analysis were derived from the Singapore Mental Health Study, a cross-sectional epidemiological survey of a representative sample of the adult resident population of Singapore. Diagnoses of psychiatric disorders were established using the Composite International Diagnostic Interview version 3.0. A modified version of the Composite International Diagnostic Interview 3.0 checklist of chronic medical disorders was used, in which the chronic medical disorders were reclassified into eight types of physical disorders. Chronic pain disorders included arthritis or rheumatism, back problems including disk or spine problems, and migraine headaches.

RESULTS: The lifetime prevalence estimates for arthritis, back pain and migraine in the Singapore general population were $6.0 \% \quad(n=282)$, $7.0 \%(\mathrm{n}=436)$ and $5.6 \%(\mathrm{n}=446)$, respectively. After adjusting for sociodemographic factors, comorbid pain disorders and the presence of other chronic physical conditions, migraine remained significantly associated with major depressive disorder (adjusted $\mathrm{OR}=2.4$ ), generalized anxiety disorder (adjusted $\mathrm{OR}=3.0$ ) and alcohol use disorders (adjusted $\mathrm{OR}=2.1$ ), while back pain was significantly associated with major depressive disorder (adjusted OR=2.0).

CONCLUSIONS: The significant association between pain and psychiatric disorders emphasizes the need to screen individuals with chronic pain conditions for psychiatric disorders, particularly depression. There is a need to develop integrated pharmacological and psychological treatments for both conditions.

Key Words: Alcohol use disorders; Arthritis; Back Pain; Major depressive disorder; Migraine

\section{La morbidité psychiatrique en cas de douleur chronique : les résultats de l'étude sur la santé mentale à Singapour}

HISTORIQUE : La douleur chronique est un problème courant dans l'ensemble de la population. Des études fondées sur des échantillons cliniques ou sur des enquêtes épidémiologiques démontrent qu'elle s'associe à des troubles psychiatriques.

OBJECTIFS : Établir la prévalence, les corrélats et les comorbidités des troubles de douleur chronique au sein de la population adulte de Singapour. MÉTHODOLOGIE : Les données utilisées dans la présente analyse sont dérivées de l'étude sur la santé mentale à Singapour, une étude épidémiologique transversale auprès d'un échantillon représentatif des habitants adultes de Singapour. Les chercheurs ont établi les diagnostics de troubles psychiatriques au moyen de la version 3 de l'entrevue composite diagnostique internationale sur la santé mentale dans le monde. Ils ont utilisé une version modifiée de la liste de cette entrevue, dans laquelle les troubles médicaux chroniques étaient reclassés en huit troubles physiques. Les troubles de douleur chronique incluaient l'arthrite ou les rhumatismes, les maux de dos, y compris les troubles dorsaux ou les troubles de la colonne vertébrale, et les migraines.

RÉSULTATS : Dans l'ensemble de la population de Singapour, l'estimation de la prévalence d'arthrite, de maux de dos et de migraine au cours de la vie s'élevait à 6,0 \% ( $n=282), 7,0 \%(n=436)$ et 5,6\% $(n=446)$, respectivement. Après rajustement compte tenu des facteurs sociodémographiques, des douleurs comorbides et d'autres troubles physiques chroniques, la migraine demeurait associée de manière significative au trouble dépressif majeur (RR rajusté $=2,4)$, au trouble anxieux généralisé ( $R R$ rajusté=3,0) et aux troubles liés à l'alcool (RR rajusté=2,1), tandis que les maux de dos s'associaient de manière significative au trouble dépressif majeur $(R R$ rajusté $=2,0)$.

CONCLUSIONS : L'association significative entre la douleur et les troubles psychiatriques fait ressortir la nécessité de procéder au dépistage des troubles psychiatriques, notamment la dépression, chez les personnes qui souffrent de douleurs chroniques. On a besoin de mettre au point des traitements pharmacologiques et psychologiques intégrés pour ces deux types de problèmes.

This association has important clinical implications because patients with psychiatric disorders often present to their primary care provider with pain as the initial reason for seeking treatment, and the lack of awareness of the association may lead to the underdiagnosis and undertreatment of the associated psychiatric disorder. Studies involving patients with chronic pain have shown that coexisting psychiatric disorders are associated with disability and poorer treatment outcomes $(13,14)$ and, similarly, the presence of pain in patients with major depressive disorder (MDD) is associated with poorer outcomes, increased overall treatment costs, impaired productivity and poor quality of life (15-17).

The aims of the present study were to establish the prevalence, correlates and comorbidities of chronic pain disorders among the adult population of Singapore. We also assessed the quality of life and extent of role disability among individuals with chronic pain. The present study was one of the first to examine the comorbidity of common psychiatric disorders with chronic pain disorders in a community sample involving a multiethnic Asian population. 


\section{METHODS}

The data analyzed in the present study were from the Singapore Mental Health Study, a cross-sectional epidemiological survey of a representative sample of the resident population of Singapore. The target population included individuals residing in households who were 18 years of age and older and able to speak English, Mandarin or Malay. Face-toface interviews with respondents were completed between December 2009 and December 2010. The study was approved by the relevant institutional ethics committees and written informed consent was obtained from all participants and the parent/guardian of participants who were between 18 and 21 years of age. A total of 6616 respondents completed the survey, resulting in a response rate of $75.9 \%$. The Singapore Mental Health Study is described in detail elsewhere (18).

\section{Measures}

The diagnoses of psychiatric disorders were established using the World Mental Health Composite International Diagnostic Interview (CIDI) version 3.0 (19). Diagnostic modules for lifetime major depressive disorder (MDD), generalized anxiety disorder (GAD), obsessive compulsive disorder (OCD) and alcohol use disorders (ie, alcohol abuse and alcohol dependence) were included in the survey. The computerized version of the instrument (the Computer Assisted Personal Interviewing program) was used for English and Chinese language interviews. All of the modules used in the Singapore Mental Health Study were translated into Bahasa Melayu (the official language of the Malays) and were administered as a paper and pencil questionnaire. Diagnoses, according to the Diagnostic and Statistical Manual of Mental Disorders version IV, were generated by running algorithms applying the diagnostic hierarchy rules on the de-identified data by trained researchers.

A modified version of the CIDI 3.0 checklist of chronic medical disorders was used and the respondents were asked to report any of the disorders listed in the checklist. The question was read as, 'I'm going to read to you a list of health problems some people have. Has a doctor ever told you that you have any of the following...' This was followed by a list of 15 chronic physical disorders which were considered to be prevalent in Singapore's population. These disorders were then reclassified into eight types of physical disorders including chronic pain disorder (arthritis or rheumatism, back problems including disk or spine problems, migraine headaches).

The EQ-5D was used to measure health-related quality of life. The EQ-5D is a standardized measure of health status developed by the EuroQol Group. It provides a simple, generic measure of health for clinical and economic appraisal (20). It comprises a descriptive system and a visual analogue scale (VAS). The EQ-5D VAS records the respondent's self-rated health on a vertical VAS, on which the end points are labelled 'Best imaginable health state' (100) and 'Worst imaginable health state' $(0)$.

Disability was assessed using the WHO Disability Assessment Schedule (WHO-DAS-II) (21). The method described by Von Korff et al (12) was used for the measure of role disability, which was derived from the following questions included in the CIDI 3.0 30-day functioning module:

How many days of the last 30:

1) ...were you totally unable to work or carry out normal activities, because of "problems with either your physical health, your mental health, or your use of alcohol or drugs?"

2) ...were you able to work or carry out normal activities, but had to cut down on what you did, or not get as much done as usual?

3) ...did you cut back on the quality of your work or how carefully you worked?

4) ... did it take extreme effort to perform up to your usual level at work or at your other normal daily activities?

Respondents reporting no disability days on these four items received a $100 \%$ role performance score; reduced role performance was calculated by subtracting disability days from 30. A full day was subtracted for each day a person was totally unable to work. A half day was subtracted for each day a person cut back on activities. A quarter day was subtracted for each day a person cut back on the quality of work, and a quarter day was subtracted for each day a person took extreme effort to perform at the usual level. The number of days subtracted from 30 was truncated at 30 days. The resulting number of role performance days was then divided by three and multiplied by 10 , resulting in a role performance score that could range from 0 to 100 , which can be considered an estimate of the percentage of full role performance.

\section{Statistical analyses}

Statistical analyses were performed using SAS version 9.2 (SAS Institute, USA). To ensure that the survey findings were representative of the Singapore population, the data were weighted to adjust for oversampling and poststratification according to age and ethnicity distributions between the survey sample and the Singapore resident population in 2007. Descriptive analyses were performed to establish the prevalence of the three pain conditions (arthritis, back pain and migraine) and comorbid psychiatric disorders (MDD, GAD, OCD and alcohol use disorders) based on weighted data. Logistic regression analysis was used to examine the associations between the three pain conditions and sociodemographic variables as well as psychiatric disorders. To elucidate the relationship between the pain condition and psychiatric disorders, accounting for other variables that may have independent effects on psychopathology, three series of logistic regression models were used, as described by McWilliams et al (22). In the first series of logistic models, ORs for the association between the pain condition and psychiatric disorders were adjusted for demographic variables such as age, sex, ethnicity and education. The second logistic regression models were adjusted for the demographic variables and comorbid pain conditions, and the third logistic regression models were adjusted for demographic variables, comorbid pain conditions and other chronic physical conditions. The fitness of the final designbased logistic regression models were examined using the ArcherLemeshow goodness-of-fit test (23).

In addition, the mean difference of role performance and EQ-5D VAS scores among individuals with chronic pain conditions, psychiatric disorders, comorbid chronic pain-psychiatric disorder and individuals without physical and psychiatric disorders (controls) were assessed using a linear regression model. An adjusted mean difference was used to indicate reduction of role performance and EQ-5D VAS scores among individuals with chronic pain conditions, psychiatric disorders and comorbid chronic pain-psychiatric disorders compared with the controls after adjusting for sociodemographic variables. SEs and significance tests were estimated using the Taylor series' linearization method to adjust for the weighting. Multivariate significance was evaluated using Wald $\chi^{2}$ tests based on design-corrected coefficient variance-covariance matrices. Statistical significance was evaluated at the $\mathrm{P}<0.05$ level using twosided tests.

\section{RESULTS}

\section{Prevalence of pain conditions and their sociodemographic} correlates

The lifetime prevalence estimates for arthritis, back pain and migraine in the Singapore general population were $6.0 \%(n=282), 7.0 \%(n=436)$ and $5.6 \%(n=446)$, respectively. The prevalence of at least one pain condition was $15.3 \%(n=979)$. Table 1 shows the sociodemographic correlates of the three pain conditions. Age, ethnicity and sex were significantly associated with the three pain conditions. Individuals belonging to the older age groups (65 years of age and older), females, individuals with a university education and individuals earning 'above SGD 50,000', ie, of a higher socioeconomic status, were more likely to experience a pain disorder, while individuals of Malay ethnicity were less likely to experience any pain disorder.

Individuals with arthritis were more likely to be older or female, and less likely to be of Malay ethnicity (versus Chinese). Individuals 
TABLE 1

Sociodemographic correlates of three pain conditions

\begin{tabular}{|c|c|c|c|c|c|c|c|c|c|c|c|c|}
\hline \multirow{2}{*}{ Characteristic } & \multicolumn{3}{|c|}{ Any pain condition } & \multicolumn{3}{|c|}{ Arthritis } & \multicolumn{3}{|c|}{ Back pain } & \multicolumn{3}{|c|}{ Migraine } \\
\hline & \multicolumn{3}{|c|}{ Adjusted } & \multicolumn{3}{|c|}{ Adjusted } & \multicolumn{3}{|c|}{ Adjusted } & \multicolumn{3}{|c|}{ Adjusted } \\
\hline \multicolumn{13}{|l|}{ Age group, years } \\
\hline $35-49$ & $14.7 \pm 1.0$ & 1.2 & $0.9-1.5$ & $3.3 \pm 0.5$ & 3.3 & $1.4-7.8^{\ddagger}$ & $7.5 \pm 0.8$ & 1.4 & $0.9-2.1$ & $6.9 \pm 0.7$ & 0.9 & $0.6-1.5$ \\
\hline $50-64$ & $15.0 \pm 1.3$ & 1.2 & $0.8-1.7$ & $9.4 \pm 1.1$ & 8.2 & $3.5-19.3^{\ddagger}$ & $7.0 \pm 0.9$ & 1.2 & $0.7-2.0$ & $3.0 \pm 0.6$ & 0.5 & $0.3-0.9^{\dagger}$ \\
\hline$\geq 65$ & $28.0 \pm 3.2$ & 2.4 & $1.4-4.0^{\ddagger}$ & $22.4 \pm 3.0$ & 17.8 & $6.9-45.9^{\ddagger}$ & $11.7 \pm 2.3$ & 1.8 & $0.8-4.2$ & $1.8 \pm 0.9$ & 0.3 & $0.1-0.6$ \\
\hline Malay & $12.6 \pm 0.7$ & 0.8 & $0.6-0.95^{\ddagger}$ & $2.8 \pm 0.3$ & 0.3 & $0.2-0.5^{\ddagger}$ & $5.1 \pm 0.5$ & 0.7 & $0.5-0.9^{\ddagger}$ & $7.2 \pm 0.5$ & 1.6 & $1.2-2.1^{\ddagger}$ \\
\hline Indian & $17.0 \pm 0.9$ & 1.2 & $0.9-1.4$ & $5.1 \pm 0.5$ & 0.8 & $0.6-1.2$ & $7.4 \pm 0.6$ & 1.0 & $0.7-1.3$ & $7.7 \pm 0.6$ & 1.6 & $1.2-2.1^{\ddagger}$ \\
\hline Other & $23.5 \pm 2.7$ & 1.9 & $1.3-2.8^{\ddagger}$ & $3.0 \pm 0.9$ & 0.9 & $0.4-2.0$ & $14.2 \pm 2.2$ & 2.2 & $1.3-3.5$ & $8.3 \pm 1.8$ & 1.4 & $0.8-2.6$ \\
\hline \multicolumn{13}{|l|}{ Sex } \\
\hline Male & $12.4 \pm 0.9$ & 1.0 & Ref & $4.4 \pm 0.6$ & 1.0 & Ref & $7.2 \pm 0.7$ & 1.0 & Ref & $3.4 \pm 0.4$ & 1.0 & Ref \\
\hline Divorced/separated & $16.9 \pm 3.3$ & 1.2 & $0.7-2.0$ & $5.6 \pm 2.0$ & 1.1 & $0.4-2.9$ & $8.5 \pm 2.6$ & 1.8 & $0.8-3.7$ & $8.1 \pm 2.2$ & 1.3 & $0.7-2.6$ \\
\hline Widowed & $29.5 \pm 4.9$ & 1.7 & $0.9-3.2$ & $24.4 \pm 4.7$ & 2.3 & $0.9-5.4$ & $15.2 \pm 3.8$ & 3.1 & $1.2-7.8^{\ddagger}$ & $2.5 \pm 1.5$ & 0.9 & $0.3-3.0$ \\
\hline \multicolumn{13}{|l|}{ Education } \\
\hline Primary and below & $18.9 \pm 1.8$ & 1.0 & Ref & $13.2 \pm 1.6$ & 1.0 & Ref & $6.6 \pm 1.1$ & 1.0 & Ref & $3.1 \pm 0.7$ & 1.0 & Ref \\
\hline Secondary & $15.6 \pm 1.2$ & 1.2 & $0.8-1.8$ & $7.3 \pm 1.0$ & 1.7 & $0.8-3.6$ & $7.3 \pm 0.9$ & 0.7 & $0.4-1.4$ & $5.3 \pm 0.7$ & 0.7 & $0.4-1.4$ \\
\hline $\begin{array}{l}\text { Pre-university/junior } \\
\text { college/diploma }\end{array}$ & $13.5 \pm 1.3$ & 1.3 & $0.9-1.8$ & $2.9 \pm 0.7$ & 1.9 & $0.9-3.8$ & $7.0 \pm 1.0$ & 1.1 & $0.7-1.8$ & $6.2 \pm 0.8$ & 1.0 & $0.6-1.6$ \\
\hline Vocational & $14.1 \pm 2.0$ & 1 & $0.8-1.5$ & $3.0 \pm 1.1$ & 1.1 & $0.5-2.4$ & $8.2 \pm 1.7$ & 1.0 & $0.6-1.6$ & $5.3 \pm 1.2$ & 1.0 & $0.6-1.5$ \\
\hline University & $13.9 \pm 1.3$ & 1.6 & $1.02-2.4^{\dagger}$ & $2.0 \pm 0.5$ & 2.2 & $0.8-5.8$ & $6.5 \pm 0.9$ & 1.7 & $0.9-3.1$ & $7.7 \pm 1$ & 0.9 & $0.5-1.7$ \\
\hline \multicolumn{13}{|l|}{ Employment } \\
\hline Employed & $14.0 \pm 0.7$ & 1.0 & Ref & $3.9 \pm 0.4$ & 1.0 & Ref & $6.4 \pm 0.5$ & 1.0 & Ref & $6.2 \pm 0.5$ & 1.0 & Ref \\
\hline
\end{tabular}

Bolded values indicate statistically significant differences. ${ }^{*}$ Multiple logistic regression; ${ }^{\dagger} P<0.05 ;{ }^{\ddagger} P<0.01$. Ref Reference

TABLE 2

Prevalence of lifetime DSM-IV psychiatric disorder in three pain conditions

\begin{tabular}{|c|c|c|c|c|c|c|c|c|c|c|c|c|}
\hline \multirow{2}{*}{$\begin{array}{l}\text { Psychiatric } \\
\text { disorder }\end{array}$} & \multicolumn{3}{|c|}{ Arthritis ( $n=282)$} & \multicolumn{3}{|c|}{ Back pain $(n=436)$} & \multicolumn{3}{|c|}{ Migraine $(n=446)$} & \multicolumn{3}{|c|}{ Any pain condition $(n=979)$} \\
\hline & $\%$ & Crude OR & $95 \% \mathrm{Cl}$ & $\%$ & Crude OR & $95 \% \mathrm{Cl}$ & $\%$ & Crude OR & $95 \% \mathrm{Cl}$ & $\%$ & Crude OR & $95 \% \mathrm{Cl}$ \\
\hline GAD & 1.4 & 1.7 & $0.4-6.2$ & 1.2 & 1.4 & $0.5-3.7$ & 3.2 & 4.5 & $2.0-10.3^{\dagger}$ & 1.5 & 1.9 & $0.9-4.0$ \\
\hline AUD & 4.7 & 1.3 & $0.7-2.8$ & 5.3 & 1.6 & $0.9-2.8$ & 7.8 & 2.4 & $1.4-4.2^{\dagger}$ & 5.6 & 1.7 & $1.1-2.7^{\dagger}$ \\
\hline
\end{tabular}

${ }^{*}$ Crude OR significant at $P<0.05 ;{ }^{\dagger}$ OR significant at $P<0.01$. AUD Alcohol use disorders; DSM Diagnostic and Statistical Manual of Mental Disorders; GAD Generalized anxiety disorder; MDD Major depressive disorder; OCD Obsessive-compulsive disorder;

with back pain were also less likely to be of Malay ethnicity and were more likely to be widowed (versus single). Individuals of Malay and Indian ethnicities and females were more likely to experience migraines; however, individuals 50 to 64 years of age were less likely to experience migraines versus individuals 18 to 34 years of age.

Prevalence of psychiatric disorders in the pain conditions

Table 2 presents the prevalence of psychiatric disorders in the three pain conditions. Generally, the prevalence of each psychiatric disorder was higher in individuals with each pain condition than in individuals without pain conditions. The prevalence of MDD was significantly higher among individuals with back pain and migraine than in individuals without these conditions. The prevalence of GAD, OCD and alcohol use disorders was also significantly higher among individuals with migraine compared with individuals without the condition.

Relationship between pain conditions and psychiatric disorders Table 3 presents the relationship between the three pain conditions and psychiatric disorders. The first model of multiple logistic regression analysis adjusted for demographic variables shows that each pain condition was significantly associated with psychiatric disorders other than OCD. Migraine was found to be strongly associated with MDD, GAD and alcohol use disorders, while arthritis was associated with MDD and alcohol use disorders, and back pain was only associated 
TABLE 3

Relationship between three pain conditions and DSM-IV psychiatric disorders

\begin{tabular}{|c|c|c|c|c|c|c|}
\hline & \multicolumn{2}{|c|}{ Model 1} & \multicolumn{2}{|c|}{ Model 2} & \multicolumn{2}{|c|}{ Model 3} \\
\hline & Adj OR & $95 \% \mathrm{Cl}$ & Adj OR & $95 \% \mathrm{Cl}$ & Adj OR & $95 \% \mathrm{Cl}$ \\
\hline \multicolumn{7}{|l|}{ MDD } \\
\hline Arthritis & 2.6 & $1.4-4.8^{\dagger}$ & 1.9 & $1.0-3.7^{*}$ & 1.8 & $0.9-3.4$ \\
\hline Back pain & 2.5 & $1.6-4.0^{\dagger}$ & 2.0 & $1.3-3.2^{\dagger}$ & 2.0 & $1.2-3.1^{*}$ \\
\hline Migraine & 2.9 & $1.9-4.3^{\dagger}$ & 2.4 & $1.6-3.8^{\dagger}$ & 2.4 & $1.5-3.7^{\dagger}$ \\
\hline \multicolumn{7}{|l|}{ GAD } \\
\hline Arthritis & 3.0 & $0.7-12.4$ & 2.3 & $0.6-8.8$ & 2.0 & $0.6-6.7$ \\
\hline Back pain & 1.6 & $0.6-4.4$ & 1.1 & $0.4-3.4$ & 1.4 & $0.5-3.7$ \\
\hline Migraine & 3.5 & $1.5-8.1^{\dagger}$ & 3.2 & $1.6-6.5^{\dagger}$ & 3.0 & $1.5-5.5^{\dagger}$ \\
\hline \multicolumn{7}{|l|}{ OCD } \\
\hline Arthritis & 1.9 & $0.8-4.6$ & 1.6 & $0.6-4.0$ & 1.4 & $0.5-3.7$ \\
\hline Back pain & 1.8 & $0.9-3.4$ & 1.6 & $0.9-3.2$ & 1.7 & $0.9-3.3$ \\
\hline Migraine & 1.6 & $0.9-2.9$ & 1.4 & $0.8-2.6$ & 1.1 & $0.6-2.2$ \\
\hline \multicolumn{7}{|l|}{ AUD } \\
\hline Arthritis & 2.6 & $1.2-5.8^{*}$ & 2.3 & $1.0-5.2^{*}$ & 2.2 & $0.9-5.3$ \\
\hline Back pain & 1.4 & $0.7-2.7$ & 1.1 & $0.6-2.2$ & 1.1 & $0.6-2.2$ \\
\hline Migraine & 3.0 & $1.6-5.4^{\dagger}$ & 2.8 & $1.5-5.0^{\dagger}$ & 2.1 & $1.1-4.0^{*}$ \\
\hline
\end{tabular}

Model 1: Adjusted (Adj) ORs and 95\% Cls were derived from multiple logistic regression model adjusted for demographic variables (ie, age, sex, ethnicity and education); Model 2: Adj ORs and 95\% Cls were derived from multiple logistic regression model adjusted for demographic variables (ie, age, sex, ethnicity and education) and the other two pain conditions; Model 3: Adj ORs and 95\% Cls were derived from multiple logistic regression model adjusted for demographic variables (ie, age, sex, ethnicity and education), the other two pain conditions and the presence of other 14 chronic medical conditions; *Adj OR significant at $P<0.05 ;{ }^{\dagger}$ Adj OR significant at $P<0.01$. AUD Alcohol use disorders; DSM Diagnostic and Statistical Manual of Mental Disorders; GAD Generalized anxiety disorder; MDD Major depressive disorder; OCD Obsessive-compulsive disorder with MDD. In the analysis that adjusted for demographic variables and other pain conditions (Model 2), these associations remained significant. Additional adjustment for the presence of the other 14 chronic physical conditions in the final model (Model 3) revealed that only a few pain conditions remained significantly associated with psychiatric disorders. Migraine remained significantly associated with MDD (adjusted $\mathrm{OR}=2.4$ ), GAD (adjusted $\mathrm{OR}=3.0$ ) and alcohol use disorders (adjusted $\mathrm{OR}=2.1$ ), while back pain was significantly associated with MDD (adjusted $\mathrm{OR}=2.0$ ),

Additional multiple logistic regression models were used to examine the association between mutually exclusive pain conditions and psychiatric disorders adjusted for demographic variables (Table 4). In this analysis, three pain conditions (arthritis, back pain and migraine) were recorded as a single dependent categorical variable with five mutually exclusive groups comprising: individuals without pain conditions as controls; arthritis only; back pain only; migraine only; and comorbid pain conditions. Individuals with back pain (adjusted $\mathrm{OR}=1.9$ ) and migraine (adjusted $\mathrm{OR}=2.7$ ) were more likely to have MDD than individuals without pain conditions.

Role performance and health-related quality of life

Table 5 presents the mean and adjusted mean difference of role performance and EQ-5D VAS scores among individuals with chronic pain conditions, psychiatric disorders, comorbid chronic pain-psychiatric disorder and controls. The mean role performance and EQ-5D VAS scores were significantly lower in individuals with chronic pain conditions, psychiatric disorders and comorbid chronic pain-psychiatric disorders compared with individuals without chronic pain or psychiatric disorders. After adjusting for sociodemographic variables, the reduction in role performance and EQ-5D VAS scores were highest among individuals with comorbid chronic pain-psychiatric disorder compared with individuals without chronic pain or psychiatric disorders. The adjusted mean difference in role performance and EQ-5D VAS scores were $5.9 \%$ and $12.4 \%$, respectively.

\section{DISCUSSION}

The lifetime prevalence of at least one pain condition was $15.3 \%$ in our sample. This is lower than that reported by the World Mental

TABLE 4

Relationship between mutually exclusive chronic pain conditions and DSM-IV psychiatric disorder

\begin{tabular}{|c|c|c|c|c|c|c|c|c|}
\hline & \multicolumn{2}{|c|}{ MDD } & \multicolumn{2}{|c|}{ GAD } & \multicolumn{2}{|c|}{ OCD } & \multicolumn{2}{|c|}{ AUD } \\
\hline & Adjusted OR* & $95 \% \mathrm{Cl}$ & Adjusted OR $^{\dagger}$ & $95 \% \mathrm{Cl}$ & Adjusted OR* & $95 \% \mathrm{Cl}$ & Adjusted OR* & $95 \% \mathrm{Cl}$ \\
\hline Arthritis only ( $n=181)$ & 1.5 & $0.6-3.8$ & 0.2 & $0.02-1.8$ & 1.6 & $0.5-5.2$ & 2.5 & $0.9-6.4$ \\
\hline Migraine only $(n=338)$ & 2.7 & $1.7-4.3^{\S}$ & 1.2 & $0.6-2.5$ & 1.3 & $0.7-2.6$ & 1.8 & $0.9-3.7$ \\
\hline Comorbid pain conditions ( $n=17$ ) & 1.6 & $0.4-6.9$ & - & - & 1.0 & $0.1-8.0$ & - & - \\
\hline
\end{tabular}

${ }^{*}$ Adjusted $\mathrm{OR}$ and $95 \% \mathrm{Cls}$ were derived from multiple logistic regression model adjusted for demographic variables (ie, age, sex, ethnicity, and education); ${ }^{\dagger}$ Individuals without any of the three pain conditions were treated as the reference category. The other pain groups were mutually exclusive. ${ }^{\ddagger} A d j u s t e d ~ O R$ significant at $P<0.05 ;{ }^{\S}$ Adjusted OR significant at $P<0.01$. AUD Alcohol use disorders; DSM Diagnostic and Statistical Manual of Mental Disorders; GAD Generalized anxiety disorder; MDD Major depressive disorder; OCD Obsessive-compulsive disorder

TABLE 5

Role performance and EQ-5D visual analogue scale scores among those with chronic pain conditions, psychiatric disorders, comorbid chronic pain-psychiatric disorder and controls

\begin{tabular}{|c|c|c|c|c|c|c|}
\hline & \multicolumn{3}{|c|}{ Role performance } & \multicolumn{3}{|c|}{ EQ-5D Visual analogue scale scores } \\
\hline & Mean \pm SE & $\begin{array}{l}\text { Adjusted mean } \\
\text { difference } \pm S E^{*}\end{array}$ & $\mathbf{P}$ & Mean \pm SE & $\begin{array}{l}\text { Adjusted mean } \\
\text { difference } \pm S E^{\star}\end{array}$ & $\mathbf{P}$ \\
\hline Any chronic pain condition $(n=779)$ & $95.1 \pm 0.8$ & $-2.6 \pm 0.9$ & 0.003 & $80.9 \pm 0.8$ & $-3.0 \pm 0.8$ & 0.0002 \\
\hline Any psychiatric disorder $(n=624)$ & $94.9 \pm 0.8$ & $-2.9 \pm 0.8$ & 0.001 & $79.0 \pm 0.9$ & $-5.7 \pm 1.0$ & $<0.001$ \\
\hline $\begin{array}{l}\text { Comorbid chronic pain condition and psychiatric } \\
\text { disorder }(n=200)\end{array}$ & $91.8 \pm 2.2$ & $-5.9 \pm 2.2$ & 0.008 & $72.6 \pm 1.8$ & $-12.4 \pm 1.8$ & $<0.001$ \\
\hline No chronic pain condition or psychiatric disorder $(n=5013)$ & $97.7 \pm 0.2$ & Reference & - & $84.4 \pm 0.3$ & Reference & - \\
\hline
\end{tabular}

${ }^{*}$ Adjusted mean difference and SE were derived from the multiple linear regression model adjusted for demographic variables (ie, age, sex, ethnicity and education). Individuals without any chronic pain conditions and psychiatric disorders were treated as the reference category. The other groups were mutually exclusive 
Health surveys (7.3\% in developed countries and $41.1 \%$ in developing countries) (2). The World Mental Health surveys assessed pain conditions using a standard chronic condition checklist (adapted and used in the present study), although prevalence was recorded for a 12 -month period compared with the lifetime prevalence figures reported in our study. The lifetime prevalence estimates for arthritis, back pain and migraine in the Singapore general population were $6.0 \%, 7.0 \%$ and $5.6 \%$ respectively. The prevalence of individual pain conditions was also lower in Singapore compared with those reported in Western populations. Studies from the United States have reported that $22.2 \%$ of adults (18 years of age and older) had self-reported doctor-diagnosed arthritis (24), while a Canadian population survey reported the prevalence of arthritis or rheumatism to be 13\% (25). Freburger et al (26) reported the prevalence of chronic low back pain to be $10.2 \%$ in a cross-sectional telephone survey of a representative sample of households in North Carolina (USA), while the prevalence of low back pain was reported to be $15 \%$ in the Canadian population (25). The one-year prevalence of migraine in the United States among adults, using strict diagnostic criteria, was $18 \%$ in women and $6.5 \%$ in men. Prevalence was highest in individuals with lower income, individuals between 25 and 55 years of age, women and white individuals (27). While migraine is prevalent in all countries, studies suggest that the prevalence is highest in the Americas, intermediate in Europe, and lowest in Africa and Asia (28).

Similar to findings reported by McWilliams et al (22), individuals with one or more pain conditions were more likely to be female and older. Similarly, a study from Hong Kong found that older age and female sex were risk factors for pain (1). We also found that individuals with higher income were more likely to experience a pain disorder. Lee et al (29) reported that among Chinese adults in Hong Kong, individuals from middle-income groups had a significant association with headache and spinal pain. They postulated that individuals from middle-income groups were more likely to be office workers and, thus, ergonomic stress and sedentary lifestyles could contribute to the association. This may account for the increased risk among individuals with higher incomes in our sample. Ethnicity also appears to play a role in chronic pain conditions; while individuals of Malay ethnicity were less likely to experience any pain disorder, specifically arthritis and back pain, they were more likely to experience migraine than the Chinese. Studies involving the clinical and general population in Singapore have found ethnic differences among headache patients: Khu et al (30) reported a preponderance of non-Chinese females among headache patients in their clinical sample, while Ho et al (31) reported that nonChinese experienced more migrainous headaches than Chinese in a national survey. However, few studies have explored the ethnic differences in other pain conditions locally, and we are unable to explain the reasons for the differences observed in our sample.

The association of the three pain conditions (arthritis, back pain and migraine) with psychiatric disorders (MDD, GAD and alcohol use disorders) other than OCD remained after adjusting for sociodemographic variables and the presence of another pain condition. Migraine remained strongly associated with all three disorders (MDD, GAD and alcohol use disorders) and arthritis with two disorders (MDD and alcohol use disorders), while back pain was associated only with MDD. Thus, in our sample, the association with MDD was the most robust, with all three pain conditions showing significant association with MDD even after adjusting for confounders. When we further adjusted for the presence of the other 14 chronic physical conditions, only migraine remained significantly associated with MDD and alcohol use disorders, while back pain was significantly associated with MDD. This finding is consistent with that reported by McWilliams et al (22), ie, depression was strongly associated with pain conditions; however, we did not find an association of any of the pain conditions with anxiety disorders, unlike several other studies that have found pain conditions to be more strongly associated with anxiety disorder than with depression $(22,32)$. This suggests that the association between pain conditions in our sample and GAD reflects an association between health problems and psychopathology in general, rather than a more specific association between pain conditions alone and GAD and, therefore, disappears when we adjust for other comorbid physical conditions.

Our study is one of the first to report an association between migraine and alcohol use disorders. Studies have suggested that alcohol is a trigger for migraine and that alcohol consumption is lower among individuals with migraine (33). However, a study by MildeBusche et al (34) found that high consumption of cocktails was associated with both migraine and tension-type headaches in adolescents. Because the present study was cross-sectional in nature, we were unable to establish whether alcohol abuse and headaches occurred at the same or different points of time in the respondent's life.

Due to the cross-sectional nature of the present study, we could not establish the causality between pain and psychiatric disorders. A bidirectional relationship between pain and psychopathology has been suggested. Gureje et al (10) reported that pain at baseline predicted new onset of depression over 12 months and vice versa. A recent longitudinal study by Gerrits et al (35) found that pain was associated with a worsening course of depressive symptoms and that chronic pain variables were strong predictors of chronicity of depression. Various mechanisms have been proposed to explain the association between pain and depression. These include shared pathophysiological pathways such as inflammatory processes, common neural pathways $(36,37)$ and genetic factors $(38,39)$.

Comorbidity of pain and psychiatric disorders contributed significantly to the reduced quality of life and role functioning in our sample. Von Korff et al (12) found that significant decrement in full role performance among individuals with spinal pain was associated with physical and psychiatric comorbidities. In a longitudinal study of patients seeking treatment for primary headache disorders (40), individuals with a depressive disorder reported more headache days, greater headache disability and poorer quality of life compared with patients with no psychiatric disorders at baseline. After six months of therapy, patients with depressive disorders were comparable with patients with no psychiatric disorders in headache days and headache severity, but continued to report greater disability and poorer quality of life than patients with no psychiatric diagnoses. The authors suggested that "improvements might be greater if pharmacotherapies are combined with biopsychosocial interventions (eg, cognitive behavioral stress management interventions) that intervene not only on the patients' headache characteristics but on important social and emotional aspects of their lives". Tunks et al (41) have similarly suggested that patients of chronic pain should be assessed for abuse, depression, stress and poor coping skills and recommended that chronic pain management must include treatment of psychological comorbidity and psychological rehabilitation.

The main limitation of our study was that we established the presence of chronic physical disorders through self-report. Research has shown that checklists provide useful information about both treated and untreated chronic conditions (42) and that self-report of chronic physical conditions shows moderate to high agreement with data from medical records (43). However, a single-item self-report measure is not as precise and reliable as a structured interview. We also did not establish the onset, duration and course of the pain condition in our sample; thus, the temporal relationship between pain and the psychiatric disorders could not be established.

These limitations notwithstanding, the present study involved a large multiethnic Asian population. It also used a structured instrument to determine psychiatric diagnosis, and examined multiple chronic pain conditions and the effect of comorbid pain and psychiatric disorders on quality of life and productivity - for which there is scant information in the extant literature. The present study was one of the first to examine the association of chronic pain conditions with psychiatric disorders in a multiethnic Asian community sample. The lack of association between anxiety disorders and chronic pain conditions should be investigated further to determine whether it is a finding unique to Asian populations. We have established an association between migraine and alcohol use disorders that has not been previously reported. 
The significant association between pain and psychiatric disorders emphasizes the need for screening individuals with chronic pain conditions for psychiatric disorders, particularly depression. There is a need to develop integrated pharmacological and psychological treatments for both conditions. Elucidating the temporal relationship could lead to appropriate preventive measures.

ACKNOWLEDGEMENT: The authors thank Ms Saleha Othman for her help in formatting the manuscript.

FUNDING SOURCES: This research was supported by funding from the Singapore Millennium Foundation and the Ministry of Health, Singapore.

\section{REFERENCES}

1. Ng KF, Tsui SL, Chan WS. Prevalence of common chronic pain in Hong Kong adults. Clin J Pain 2002;18:275-81.

2. Tsang A, Von Korff M, Lee S, et al. Common chronic pain conditions in developed and developing countries: Gender and age differences and comorbidity with depression-anxiety disorders. J Pain 2008;9:883-91.

3. Demyttenaere K, Bonnewyn A, Bruffaerts R, Brugha T, De Graaf R, Alonso J. Comorbid painful physical symptoms and depression: Prevalence, work loss, and help seeking. J Affect Dis 2006;92:85-193.

4. Ohayon MM, Schatzberg AF. Using chronic pain to predict depressive morbidity in the general population. Arch Gen Psychiatry 2003;60:39-47.

5. Breivik H, Collett B, Ventafridda V, Cohen R, Gallacher D. Survey of chronic pain in Europe: Prevalence, impact on daily life, and treatment. Eur J Pain 2006;10:287-333.

6. Elliott AM, Smith BH, Hannafold PC, Smith WC, Chambers WA. The course of chronic pain in the community: Results of a 4-year follow-up study. Pain 2002;99:299-307.

7. Dersh J, Gatchel RJ, Mayer T, Polatin P, Temple OR. Prevalence of psychiatric disorders in patients with chronic disabling occupational spinal disorders. Spine 2006;31:1156-62.

8. Knaster P, Karlsson H, Estlander AM, Kalso E. Psychiatric disorders as assessed with SCID in chronic pain patients: The anxiety disorders precede the onset of pain. Gen Hosp Psychiatry 2012;34:46-52.

9. Demyttenaere K, Bruffaerts R, Lee S, et al. Mental disorders among persons with chronic back or neck pain: Results from the World Mental Health Surveys. Pain 2007;129:332-42.

10. Gureje O, Von Korff M, Kola L, et al. The relation between multiple pains and mental disorders: Results from the World Mental Health Surveys. Pain 2008;135:82-91.

11. Bair MJ, Robinson RL, Katon W, Kroenke K. Depression and pain comorbidity: A literature review. Arch Intern Med 2003;163:2433-45.

12. Von Korff M, Crane P, Lane M, et al. Chronic spinal pain and physical-mental comorbidity in the United States: Results from the national comorbidity survey replication. Pain 2005;113:331-9.

13. Nicholas MK, Coulston CM, Asghari A, Malhi GS. Depressive symptoms in patients with chronic pain. Med J 2009;190: S66-70.

14. Börsbo B, Peolsson M, Gerdle B. The complex interplay between pain intensity, depression, anxiety and catastrophising with respect to quality of life and disability. Disabil Rehabil 2009;31:1605-13.

15. Gameroff MJ, Olfson M. Major depressive disorder, somatic pain, and health care costs in an urban primary care practice. J Clin Psychiatry 2006;67:1232-9.

16. Muñoz RA, McBride ME, Brnabic AJ, et al. Major depressive disorder in Latin America: The relationship between depression severity, painful somatic symptoms, and quality of life. J Affect Disord 2005;86:93-8.

17. Li HC, Zhang MY, Wang G, et al. Association between painful physical symptoms and clinical outcomes in Chinese patients with major depressive disorder: A three-month observational study. Chin Med J (Engl) 2010;123:2063-9.

18. Subramaniam M, Vaingankar J, Heng D, et al. The Singapore Mental Health Study: An overview of the methodology. Int J Methods Psychiatr Res 2012;21:149-57.

19. Kessler RC, Ustun TB. The World Mental Health (WMH) Survey Initiative version of the World Health Organization (WHO)
Composite International Diagnostic Interview (CIDI). Int J Methods Psychiatr Res 2004;13:93-121.

20. EuroQol Group. EuroQol - a new facility for the measurement of health-related quality of life. Health Policy 1990;16:199-208.

21. Chwastiak LA, Von Korff M. Disability in depression and back pain: Evaluation of the World Health Organization Disability Assessment Schedule (WHO DAS II) in a primary care setting. J Clin Epidemiol 2003;56:507-14.

22. McWilliams LA, Goodwin RD, Cox BJ. Depression and anxiety associated with three pain conditions: Results from a nationally representative sample. Pain 2004;111:77-83.

23. Archer KJ, Lemeshow S. Goodness-of-fit test for a logistic regression model estimated using survey sample data. Stata J 2006;6:97-105.

24. Cheng YJ, Hootman JM, Murphy LB, Langmaid GA, Helmick CG. Prevalence of doctor-diagnosed arthritis and arthritis-attributable activity limitation - United States, 2007-2009. Morb Mortal Wkly Rep 2010;59:1261-5.

25. Millar WJ. Chronic pain. Health Reports (Statistics Canada, Catalogue 82-003). 1996;7:47-53.

26. Freburger JK, Holmes GM, Agans RP, et al. The rising prevalence of chronic low back pain. Arch Intern Med 2009;169:251-8.

27. Lipton RB, Stewart WF, Diamond S, Diamond ML, Reed M. Prevalence and burden of migraine in the United States: Data from the American Migraine Study II. Headache 2001;41:646-57.

28. Lipton RB, Bigal ME, Scher AI, Stewart WE. The global burden of migraine. J Headache Pain 2003;4:S3-S11.

29. Lee S, Tsang A. A population-based study of depression and three kinds of frequent pain conditions and depression in Hong Kong. Pain Med 2009;10:155-63.

30. Khu JV, Siow HC, Ho KH. Headache diagnosis, management and morbidity in the Singapore primary care setting: Findings from a general practice survey. Singapore Med J 2008;49:774-9.

31. Ho KH, Ong BK. Headache characteristics and race in Singapore: Results of a randomized national survey. Headache 2001;41:279-84.

32. McWilliams LA, Cox BJ, Enns MW. Mood and anxiety disorders associated with chronic pain: An examination in a nationally representative sample. Pain 2003;106:127-33.

33. Panconesi A. Alcohol and migraine: Trigger factor, consumption, mechanisms. A review. J Headache Pain 2008;9:19-27.

34. Milde-Busch A, Blaschek A, Borggräfe I, Heinen F, Straube A, von Kries R. Associations of diet and lifestyle with headache in high-school students: Results from a cross-sectional study. Headache 2010;50:1104-14.

35. Gerrits MM, Vogelzangs N, van Oppen P, van Marwijk HW, Van der Horst H, Penninx BW. Impact of pain on the course of depressive and anxiety disorders. Pain 2012;153:429-36.

36. Mason P. Deconstructing endogenous pain modulation. J Neurophysiol 2005;94:1659-63.

37. Benarroch EE. Descending monoaminergic pain modulation: Bidirectional control and clinical relevance. Neurology 2008;71:217-21.

38. Zubieta JK, Heitzeg MM, Smith YR, et al. COMT val158met genotype affects mu-opioid neurotransmitter responses to a pain stressor. Science 2003;299:1240-3.

39. Holliday KL, Nicholl BI, Macfarlane GJ, Thomson W, Davies KA, McBeth J. Genetic variation in the hypothalamic-pituitary-adrenal stress axis influences susceptibility to musculoskeletal pain: Results from the EPIFUND study. Ann Rheum Dis 2010;69:556-60.

40. Heckman BD, Holroyd KA, Himawan L, et al. Do psychiatric comorbidities influence headache treatment outcomes? Results of a naturalistic longitudinal treatment study. Pain 2009;146:56-64.

41. Tunks E, Weir R, Crook J. Epidemiologic perspective on chronic pain treatment. Can J Psychiatry 2008;53:235-241

42. Knight M, Stewart-Brown S, Fletcher L. Estimating health needs: The impact of a checklist of conditions and quality of life measurement on health information derived from community surveys. J Public Health Med 2001;23:179-86.

43. US Department of Health and Human Services. Evaluation of National Health Interview Survey diagnostic reporting. Vital Health Stat 2 1994;120:1-116. 


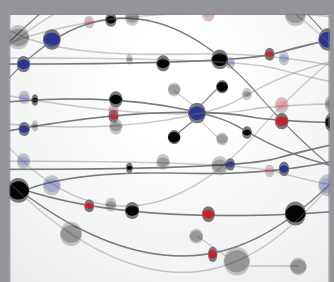

The Scientific World Journal
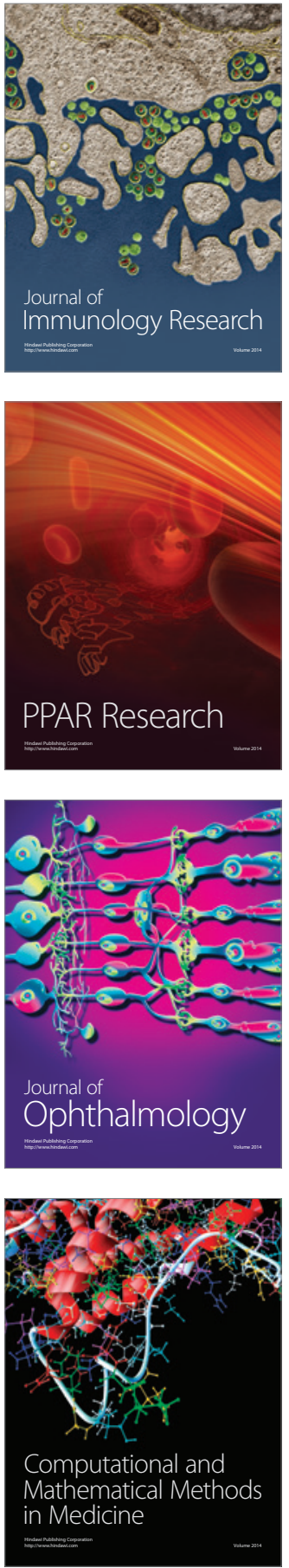

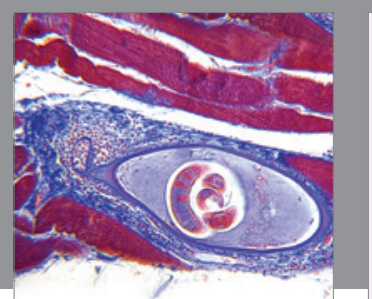

Gastroenterology Research and Practice

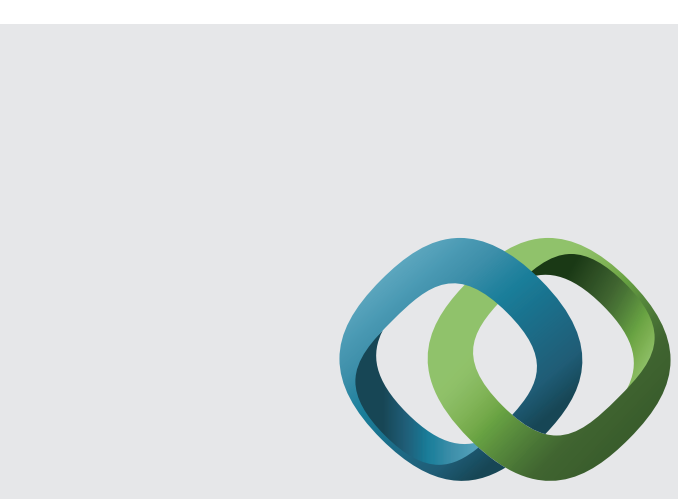

\section{Hindawi}

Submit your manuscripts at

http://www.hindawi.com
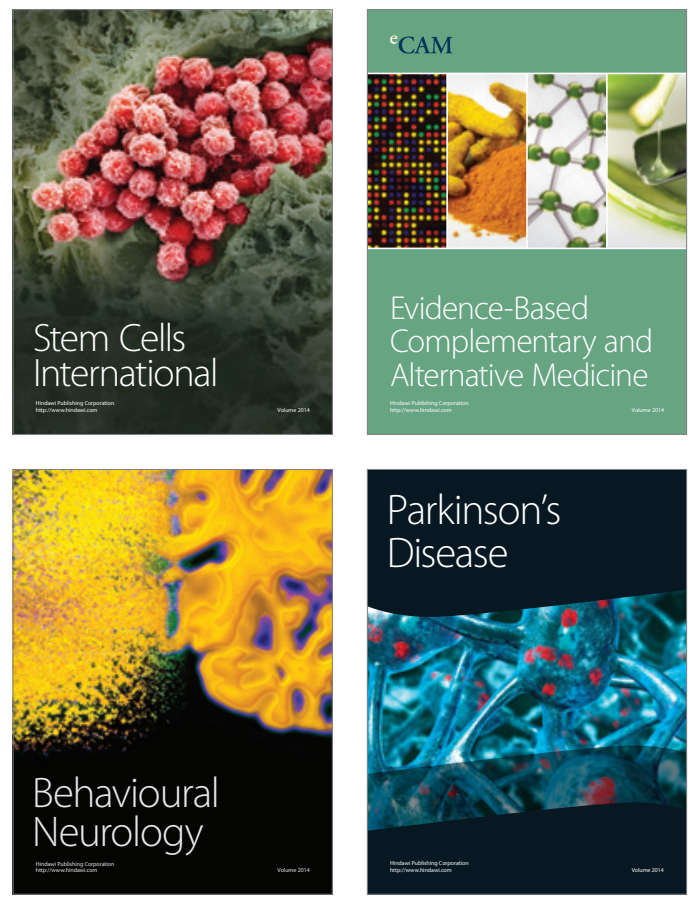
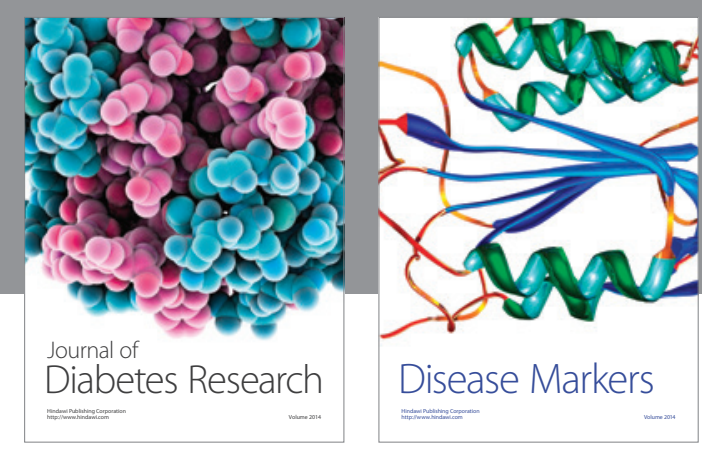

Disease Markers
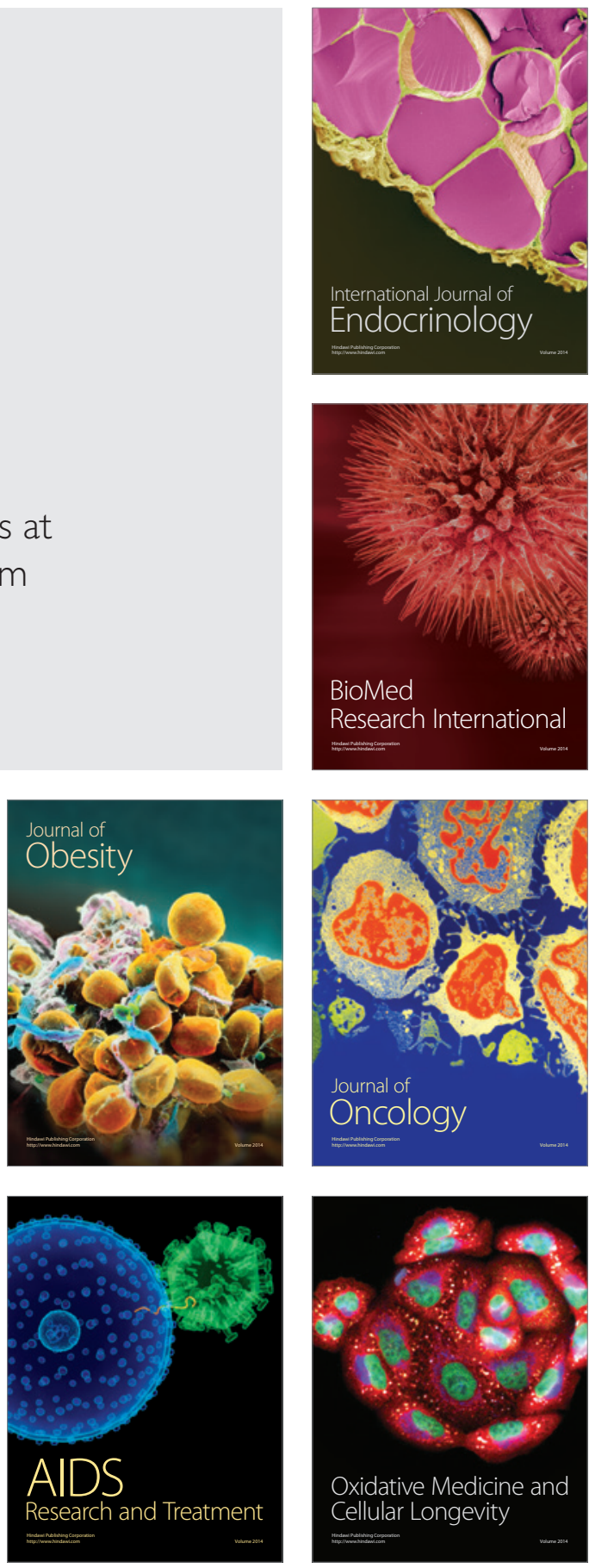